\title{
RANCANG BANGUN JARINGAN KOMPUTER MENGGUNAKAN SISTEM MANAJEMEN OMADA CONTROLLER PADA INSPEKTORAT KABUPATEN SUMBAWADENGAN METODE NETWORK DEVELOPMENT LIFE CYCLE (NDLC)
}

\author{
Yudi Mulyanto ${ }^{1}$, Satrio Budi Prakoso² \\ 1), 2) Program Studi Informatika, Universitas Teknologi Sumbawa \\ 1yudi.mulyanto@uts.ac.id, ${ }^{2}$ riobudiprakoso@gmail.com
}

\begin{abstract}
Abstraksi : Instansi pemerintah adalah organisasi yang merupakan kumpulan orang-orang yang dipilih secara khusus untuk melakukan tugas Negara sebagai bentuk pelayanan kepada orang banyak. Inspektorat Kabupaten Sumbawa merupakan instansi pemerintah yang ada di Kabupaten Sumbawa yang memiliki fungsi pengawasan, penyelenggaraan pemerintah daerah yang dipimpin oleh seorang Inspektur dalam menjalankan fungsi tersebut instansi ini belum menerapkan teknologi jaringan untuk menghubungkan antara satu bagian dengan bagian lainnya. Penelitian ini bertujuan membangun infrastruktur jaringan komputer, pada Inspektorat Kabupaten Sumbawa. Penelitian ini dalam membangun jaringan menggunakan perangkat jaringan seperti Router Mikrotik, Switch, Access Point dan perangkat pendukung lainnya Metode pengembangan jaringan menggunakan metode Network Development Life Cycle (NDLC). Dimulai dari proses analisis, perancangan, simulasi, implementasi, hingga monitoring. Instrumen teknik pengumpulan data pada penelitian menggunakan wawancara, observasi dan dokumentasi. Hasil akhir dari penelitian ini adalah membangun infrastruktur jaringan telah terhubung seluruh bagian ruangan inspektorat. Sehingga Inspektorat Kabupaten Sumbawa mampu menerapkan aktifitas digitalisasi dan teknologi jaringan seluruh pagawai yang ada di Inspektorat.
\end{abstract}

Kata Kunci: Instansi pemerintah, Router Mikrotik, NDLC

\begin{abstract}
Government agencies are organizations that are a collection of people who are specially elected to perform state duties as a form of service to the crowd. The Inspectorate of Sumbawa District is a government agency in Sumbawa Regency that has supervision function, the implementation of local government led by an inspector in carrying out this function is not yet Apply network technology to connect between one section with the other. This research aims to build a computer network infrastructure, the Inspectorate of Sumbawa District. This research in building networks using network devices such as Mikrotik routers, switches, Access points and other supporting devices network development methods using the Network Development Life Cycle (NDLC) method. Starting from the process of analysis, designing, simulation, implementation, to monitoring. The instrument of data collection techniques on research using interviews, observations and documentation. The end result of this research is building the network infrastructure has been connected throughout the room inspectorate. Therefore, the Inspectorate of Sumbawa District is able to implement the activities of digitalisation and network technology of all the Pagawai in the inspectorate.
\end{abstract}

Keywords: Government agencies, Mikrotik routers, NDLC

\section{PENDAHULUAN}

Pada era globalisasi saat ini kemajuan teknologi sangat pesat, salah satunya di bidang jaringan komputer, Dimana jaringan komputer memiliki fungsi utama untuk menghubungkan satu komputer dengan komputer lainnya dalam suatu tempat, rumah, gedung, kantor, hingga instansi-instansi pemerintah, salah satunya pada Kantor Inspektorat Kabupaten Sumbawa Besar.

Kantor Inspektorat Kabupaten Sumbawa Besar merupakan instansi pemerintah yang memiliki fungsi pengawasan, penyelenggaraan pemerintah daerah yang dipimpin oleh seorang inspektur yang bertanggung jawab langsung kepada Bupati. Kondisi saat ini dalam melaksanakan fungsi tersebut kantor inspektorat terkendala oleh belum terbentuknya jaringan komputer yang menghubungkan antara satu bagian dengan bagian lainnya, Selain itu terdapat modem wirelless pada sub-bagian perencanaan dan area jaringannya masih terbatas, dan belum adanya administrator yang dapat mengontrol perangkat jaringan tersebut, dampaknya menyebabkan aktifitas kerja pada inspektorat kabupaten Sumbawa menjadi terhambat..
Berdasarkan permasalahan tersebut peneliti akan melakukan penelitian yang berjudul "Rancang Bangun Jaringan Komputer menggunakan Sistem Manajemen Omada Controller pada Inspektorat Kabupaten Sumbawa dengan metode Network Development Life Cycle (NDLC)".

Dengan dirancang dan dibangunnya jaringan pada penelitian ini diharapkan dapat memberi kemudahan bagi para pegawai di kantor Inspektorat Kabupaten Sumbawa sehingga dengan lancarnya akses internet pada instansi tersebut dapat meningkatkan kinerja para pegawai dalam melaksanakan dan menyelesaikan pekerjaannya.

\section{TINJUAN PUSTAKA}

Ada beberapa penelitian yang telah dilakukan oleh peneliti sebelumnya yang memiliki kesamaan dengan penelitian yang akan dilakukan. Dibawah ini terdapat beberapa penelitian yang dijadikan sebagai referensi oleh penulis dalam melakukan penelitian ini.

Dalam penelitian yang dilakukan Mardhiyah berfokus pada pengembangan dan pemberian layanan jaringan di kelurahan Bintaro dengan memanfaatkan mode repeater pada access point. Sehingga dapat 
menjangkau semua bagian pada kantor tersebut tanpa penambahan perangkat terlalu banyak. Hal ini tentunya sejalan dengan penelitian yang dilakukan oleh peneliti yaitu pengadaan perangkat jaringan untuk memberikan layanan pada kantor inspektorat, selain itu kesamaan juga terdapat pada metode yang digunakan yaitu metode (NDLC) dan perbedaannya hanya terdapat pada objek penelitian dan basis yang digunakan [6].

\subsubsection{Rancang Bangun Jaringan Komputer}

Rancang bangun merupakan kegiatan menerjemahkan hasil analisa ke dalam bentuk paket perangkat lunak kemudian menciptakan sistem tersebut ataupun memperbaiki sistem yang sudah ada [3].

Jaringan Komputer adalah hubungan antara komputer yang dikoneksikan menggunakan kabel atau nirkabel (wireless) supaya bisa terkoneksi dan saling berkomunikasi [9].

Berdasarkan definisi diatas penulis menyimpulkan, rancang bangun jaringan komputer adalah suatu kegiatan menerjemahkan sistem berupa hasil analisa menjadi bentuk rancangan sistem yang nantinya dapat terhubung antara satu dengan yang lainnya dan dapat bekerja sama untuk mencapai suatu tujuan tertentu.

\subsubsection{Sistem}

Sistem adalah kumpulan komponen yang saling terkait satu dengan yang lainnya untuk mencapai tujuan tertentu [8].

Dari definisi sistem di atas, dapat penulis simpulkan bahwa sistem adalah kumpulan komponen yang saling terkait dan terhubung menjadi satu kesatuan untuk mencapai tujuan tertentu.

\subsubsection{Manajemen}

manajemen adalah ilmu dan seni yang mengatur proses pemanfaatan sumber daya manusia dan sumbersumber lainnya secara efektif dan efisien untuk mencapai suatu tujuan tertentu [4].

Dari definisi manajemen di atas, dapat penulis simpulkan bahwa manajemen adalah suatu seni dan proses untuk mengatur, mengolah, mengendalikan dan merencanakan suatu kegiatan secara optimal sehingga mencapai pada sasaran yang diinginkan.

\subsubsection{Omada Controller}

Omada Controller yang merupakan perangkat lunak manajemen untuk perangkat EAP TP-Link. Dengan perangkat lunak ini, dapat menggunakan browser web untuk mengelola perangkat Extensible Authentication Protocol (EAP) secara terpusat, seperti mengkonfigurasi EAP dalam batch dan melakukan pemantauan EAP secara waktu.

\subsubsection{Network Development Life Cycle (NDLC)}

NDLC adalah kunci dibalik proses perancangan jaringan komputer. Model ini mendefinisikan siklus proses pembangunan atau pengembangan sistem jaringan komputer [5].

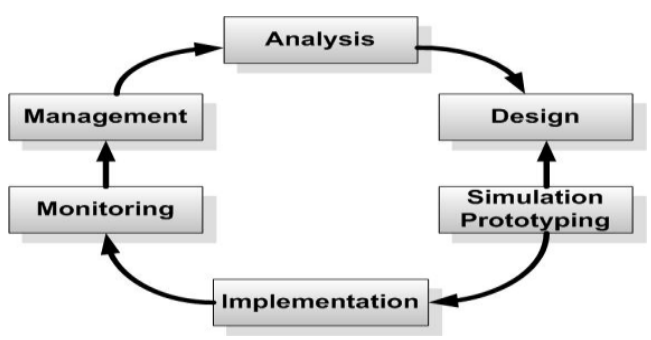

Gambar 2.1 Network Development Life Cycle (NDLC)

\section{Analysis}

Analysis Tahap awal ini dilakukan analisis kebutuhan, analisis permasalahan yang muncul, analisis keinginan user, dan analisis Topologi / jaringan yang sudah ada.

\section{Design}

Design dari data-data yang didapatkan sebelumnya, tahap design ini akan membuat gambar design topology jaringan interkoneksi yang akan dibangun, diharapkan dengan gambar ini akan memberikan gambaran seutuhnya dari kebutuhan yang ada.

\section{Simulation/Prototype}

Simulation Tahap membuat dalam bentuk simulasi dengan bantuan tools khusus di bidang network seperti Paket Tracer, hal ini dimaksudkan untuk melihat kinerja awal dari network yang akan dibangun dan sebagai bahan presentasi dan sharing dengan team work lainnya.

\section{Implementation}

Implementasi merupakan tahapan yang sangat menentukan dari berhasil atau gagalnya project yang akan dibangun dan ditahap inilah teamwork akan diuji dilapangan untuk menyelesaikan masalah teknis dan non teknis.

\section{Monitoring}

Monitoring merupakan tahapan yang penting, agar jaringan komputer dan komunikasi dapat berjalan sesuai dengan keinginan dan tujuan awal.

\section{Management}

Management untuk mengatur agar sistem yang telah dibangun dan berjalan dengan baik, serta dapat berlangsung lama dan unsur reliability terjaga

\section{METODOLOGI}

Metode penelitian yang digunakan dalam penelitian ini adalah metode kualitatif yang bersifat deskriptif [1]. Berikut ini adalah Tahapan-tahapan metode pengumpulan data dan pengembangan jaringan yaitu sebagai berikut: 


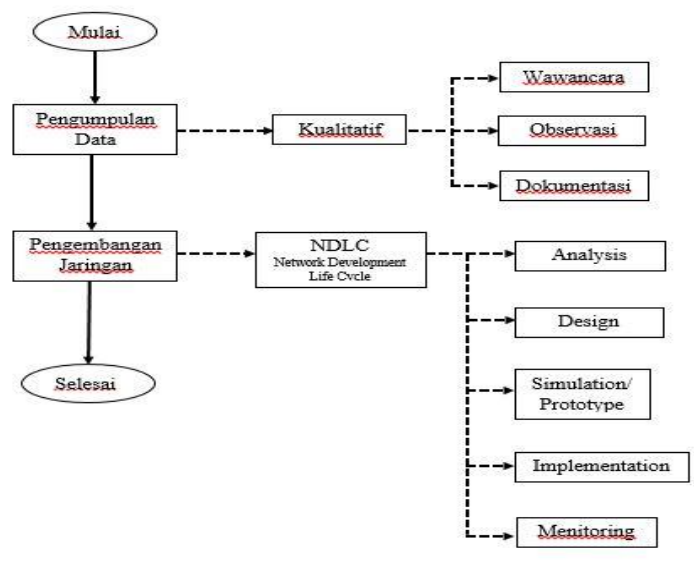

Gambar 3.1 Tahapan Metode Penelitian

\subsection{Metode Pengumpulan Data}

Pada tahapan metode pengumpulan data ini peneliti menggunakan dalam rangka pengumpulan informasi mengenai objek penelitian ini, yaitu :

\subsubsection{Wawancara}

Pada tahap ini peniliti melakukan wawancara terhadap petugas Sub-bagian perencanaan atau pegawai dari seksi lain untuk mendapatkan informasi mengenai permsalahan-permasalahan yang dihadapi.

\subsubsection{Observasi}

Pada langkah ini peneliti melakukan survey langsung di kantor Inspektorat Kabupaten Sumbawa dan observasi dilakukan sebelum pelaksanaan pengumpulan data, dimana peneliti melakukan pengenalan objek baik lingkungan kerja, bahan kajian dan objek yang diteliti.

\subsubsection{Dokumentasi}

Pada tahap ini peneliti mempelajari teori, konsep, teknik, maupun pokok pikiran dari berbagai sumber seperti, buku, majalah, jurnal, maupun artikel ilmiah lainnya yang berkaitan dengan rancang bangun jaringan.

\subsection{Metode Pengembangan Jaringan}

Pada penelitian ini peneliti menggunakan metode pengembangan jaringan Network Development Life Cycle (NDLC). Berkaitan dengan penelitian ini, penerapan setiap tahapan yang terdiri dari enam tahapan yaitu analysis, design, simulation prototyping, implementation, monitoring, management dan dari keenam tahapan-tahapan yang terdapat pada metode NDLC diatas peneliti hanya menggunakan beberapa tahapan antara lain analysis, design, simulation prototyping, implementation dan monitoring.

\subsubsection{Analysis}

Pada tahap awal ini tahapan yang dilakukan peneliti untuk menganalisis kebutuhan karyawan, menganalisi keinginan dan kondisi permasalahan yang terjadi pada jaringan di Inspektorat Kabupaten Sumbawa.

\subsubsection{Design}

Setelah mendapatkan dan mengetahui seluruh kebutuhan yang diperlukan, peneliti merancang jaringan yang akan dibangun untuk menghubungkan ke semua masing-masing ruangan yang ada di Inspektorat Kabupaten Sumbawa, dalam hal ini penliti memilih topologi yang sesuai dengan kondisi wilayah kantor Inspektorat sehingga untuk penetapan topologi peneliti menggunakan topologi star.

\subsubsection{Simulation}

Pada tahap simulation prototype ini peneliti akan membuat dalam bentuk simulasi rancangan jaringan dengan bantuan tools khusus di bidang network seperti paket tracert 7.1 karena telah dilengkapi dengan fitur perangkat hardware dibandingkan dengan versi dibawahnya, dengan begitu peneliti lebih memilih versi terbaru paket tracer 7.1 hal ini dimaksudkan untuk melihat kinerja awal dari jaringan yang akan dibangun dan sebagai bahan presentasi.

\subsubsection{Implementation}

Pada tahapan ini akan memakan waktu lebih lama dari tahapan sebelumnya. Dalam implementasi peneliti akan menerapkan semua yang telah direncanakan dan di design sebelumnya dari topologi jaringan yang diterapkan serta hasil dari simulation prototype yang telah di buat pada paket tracert. Sehingga dapat menjadi pedoman dalam memasang perangkat jaringan dan alur dari pengkabelan jaringan serta konfigurasi dari masing-masing prangkat seperti router.

\subsubsection{Monitoring}

Setelah di tahapan ini peneliti mengamati fungsi perangkat keras yang terpasang dan memantau kinerja software omada controller yang nantinya terpasang pada PC Mini Stick, selain itu monitoring terhadap performance alat, channel, access point list, dan signal list, juga menjadi prioritas yang harus dijalankan pada metode ini.

\section{HASIL DAN PEMBAHASAN}

\subsection{Hasil Pengumpulan Data}

Dari ketiga metode yang peneliti gunakan dalam pengumpulan data maka dapat diuraikan dari data-data yang berhasil terkumpul selama penelitian berlangsung dalam kurun waktu 3 bulan, berikut data-data tersebut:

\subsubsection{Wawancara}

Pada tahap wawancara dilakukan dengan wawancara langsung. Metode wawancara langsung dilakukan dengan memberikan pertanyaan langsung kepada kepala Bagian Inspektorat Kabupaten 
Sumbawa dari peroses wawancara yang dilakuakan bahwa pihak tersebut mendukung dalam pembangunan jaringan yang ada di Inspektorat Kabupaten Sumbawa.

\subsubsection{Observasi}

Setelah melakukan observasi terhadap Kantor Inspektorat Kabupaten Sumbawa, pada Sub bagian Perencanaan dan Sub bagian Umum tersebut bersedia memberikan data atau informasi terkait dengan pembangunan jaringan yang akan dibangun data yang diberikan berupa skema bangunan dan jumlah pegawai yang ada di dinas tersebut

\subsubsection{Dokumentasi}

Hasil dari proses Dokumentasi berupa foto penelitian dalam pemasangan jaringan di Inspektorat yang telah terlampirkan di lempira.

\subsection{Analysis}

Hasil dari analisis kebutuhan dalam merancang bangun jaringan yang akan diterapkan antara lain:

4.2.1 Analisis Kebutuhan Perangkat Keras

Adapun dari beberapa analisis kebutuhan perangkat keras yang dibutuhkan adalah sebagai berikut :

Tabel 4.1 Analisis Kebutuhan Perangkat Keras

\begin{tabular}{|l|l|l|}
\hline No & Perangkat Keras & \multicolumn{1}{|c|}{ Spesifikasi } \\
\hline 1 & Laptop & a. Processor AMD Dual Core E1 1200 \\
& & 1.4 GHz \\
& & b. RAM4 Gb DDR 3 \\
& & c. VGA AMD Radeon HD 7310 \\
& & d. Harddisk 320 Gb \\
\hline 2 & Mikrotik Router Board & a. 3011 UiAS-RM \\
& & b. Memory \\
& & c. Boot Loader Router Boot \\
& & d. Data Storage 64 MB \\
& & e. 10 Lan Port \\
& & f. Router OS \\
\hline 3 & Kabel Lan & a. RJ-45 \\
\hline
\end{tabular}

\subsubsection{Analisis Kebutuhan Perangkat Lunak}

Beberapa perangkat lunak yang dibutuhkan dalam membangun jaringan tersebut adalah sebagai berkut.

Tabel 4.2 Analisis Kebutuhan Perangkat Lunak

\begin{tabular}{|l|l|c|}
\hline No & Perangkat Lunak & Versi \\
\hline 1 & Windows & $7(64$ Bit $)$ \\
\hline 2 & Router Board OS & 3 \\
\hline 3 & Google Chrome & 73.0 \\
\hline 4 & Winbox & 3.16 \\
\hline 5 & Omada Controller & 3.0 .3 \\
\hline
\end{tabular}

\subsubsection{Analisis Kebutuhan Pengguna}

Pada tahapan ini penulis menguraikan kebutuhan yang pengguna lakukan dalam jaringan pada Inspektorat Kabupaten Sumbawa sebagai berikut.
A. User

Berikut merupakan fasilitas yang sering digunakan user dalam jaringan internet beserta tujuannya:

1. Media Transfer data : di tahap ini user melakukan pengambilan data dan penyimpanan data secara elektronik upload dan download

2. Chatting : kemudian di tahap ini user memanfaatkan sarana internet sebagai untuk komunikasi langsung dengan melalui tulisan dan kata-kata melalui media yang terserdia seperti facebook, whatsapp dan line.

3. Mesin Pencarian : di tahap ini user dapat mencari informasi atau pelacakan suatu informasi yang kita butuhkan secara cepat melalui media google yang tersedia.

B. Admin

Berikut merupakan fasilitas yang dilakukan oleh admin beserta tujuannya:

1. Mikrotik : Pada proses disini admin melakukan pengaturan jaringan serta perubahan alur jaringan yang diubah sesuai keperluan admin karena memiliki hak akses penuh dalam mengatur mikrotik.

2. Omada Controller: Pada tahapan ini admin dapat melihat perangkat yang telah terpasang serta memonitoring jaringan maupun perangkat yang terpasang.

\subsection{Design}

Didalam proses perancangan ini penulis menerapkan beberapa perancangan dari media kabel maupun nirkabel dalam menghubungkan di setiap masing-masing ruangan berikut uraian dari tahapan perancangan dapat dilihat dibawah ini :

\subsubsection{Perancangan Infrastruktur Jaringan}

Berikut ini merupakan bagian dari gambar infrastruktur jaringan yang akan diterapkan dibawah ini

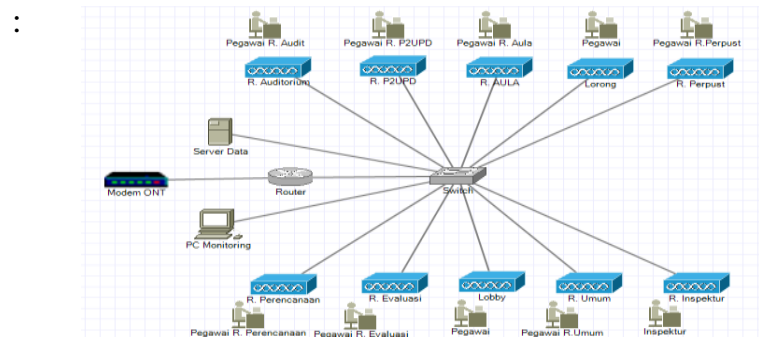

Gambar 4.1 Perancangan Infrastruktur Jaringan

\subsubsection{Desain Penempatan Jaringan Real}

Penempatan jaringan yang nantinya akan di pasang pada instansi Inspektorat Kabupaten Sumbawa yang akan digambarkan dalam bentuk sketsa dan dapat di lihat pada gambar di bawah ini:

A. Penempatan Jaringan Lantai Satu

Adapun penempatan jaringan lantai satu dapat di lihat sebagai berikut: 


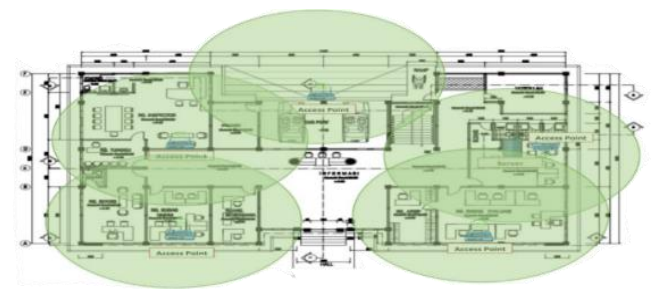

Gambar 4.2 Penempatan Jaringan Lt 1

B. Penempatan Jaringan Lantai 2

Adapun penempatan jaringan di lantai dua dapat diliat sebagai berikut :

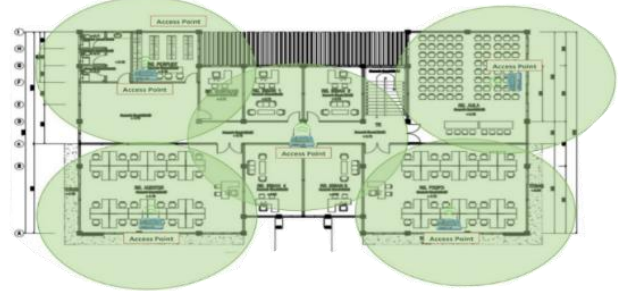

Gambar 4.3 Penempatan Jaringan Lt 2

\subsubsection{Desain Penggunaan Ip Address}

Pada tahapan ini akan digambarkan rancangan IP address yang akan digunakan dalam jaringan, dan pembagian alamat IP address ini dibagi menjadi 2 network dari router. 1 network digunakan untuk network IP LAN dan satu network digunakan untuk network IP Wifi. Pembagian IP menggunakan IP kelas $\mathrm{C}$ yang digunakan untuk jaringan LAN. Pembagian Network ada pada tabel dibawah ini :

Tabel 4.3 Pembagian IP Address

\begin{tabular}{|l|l|l|l|l|}
\hline No & Interface & $\begin{array}{l}\text { Network } \\
\text { Address }\end{array}$ & Host Range & $\begin{array}{l}\text { Broadcast } \\
\text { Address }\end{array}$ \\
\hline 1 & WAN & 192.168 .1 .64 & $192.168 .1 .1-$ & 192.168 .1 .255 \\
& & $/ 24$ & 192.168 .1 .254 & \\
\hline 2 & LAN & 192.168 .88 .1 & $192.168 .88 .1-$ & 192.168 .88 .255 \\
& & $/ 24$ & 192.168 .88 .254 & \\
\hline
\end{tabular}

\subsection{Simulation Prototype}

Ditahapan ini penulis akan melakukan pemilihan simulator yang akan digunakan dalam penelitian ini yaitu menggunakan Cisco Paket Tracer Versi 7.0, pada proses simulasi ini terdapat fitur-fitur yang memudahkan dalam merancang dan membangun jaringan yang memiliki berbagai kemampuan jaringan yang nyata dalam konfigurasinya, sehingga ini akan membuat simulasi jaringan sesuai dengan kenyataan dan dalam hal ini simulasi juga dapat memungkinkan untuk menggabungkan beberapa tingkat.

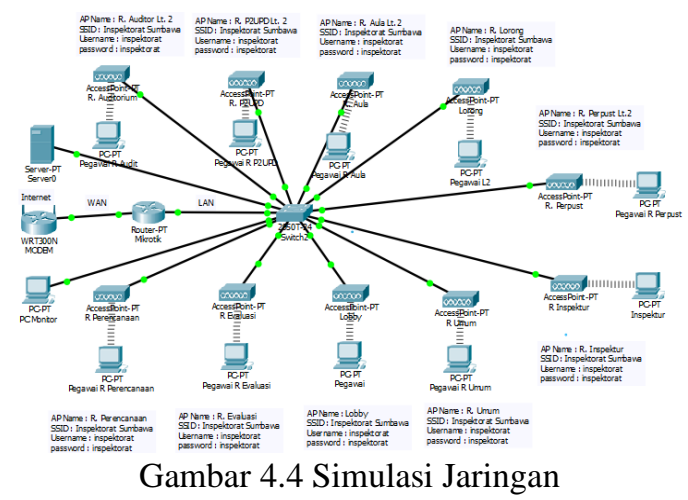

\subsection{Implementation}

Dalam mengimplementasi rancang bangun jaringan menggunakan beberapa perangkat pendukung, penulis melakukan instalasi dari pemasangan perangkat hingga settingan jaringan menggunakan aplikasi winbox untuk mengkonfigurasi serta memberikan keamanan dalam jaringan melalui mikrotik kemudian penulis menginstall aplikasi omada controller untuk memonitoring prangkat access point yang telah terpasang agar dapat memudahkan dalam mengetahui gejala pada perangkat access point tersebut.

\subsubsection{Implementasi Fisik}

Implementasi fisik terdiri dari 4 tahap yaitu instalasi rak server, instalasi jaringan acces point pada lantai 1, instalasi acces point pada lantai 2 dan instalasi perangkat omada controller berikut uraiannya :

\section{A. Instalasi Rak Server}

Adapun dari pemasangan rak server tersebut dapat diliat pada gambar dibawah ini :

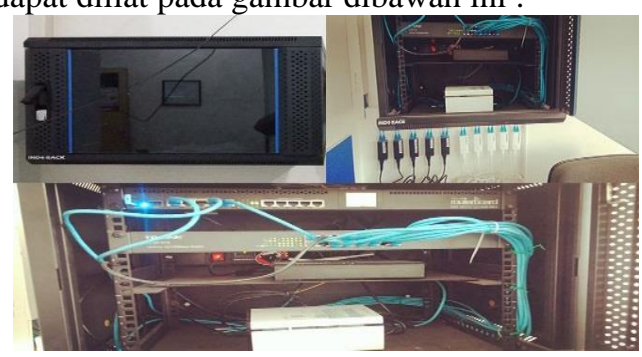

Gambar 4.5 Instalasi Rak Server

Pada gambar 4.5 diatas penulis telah memulai instalasi pemasangan rak server, semua perangkat seperti mikrotik, switch, dan server data akan diletakkan didalam rak server yang bertype WIR4504S dengan lebar $600 \mathrm{~mm}$ dan kedalaman $450 \mathrm{~mm}$ dengan 1 pintu dapat mampu menampung 4 perangkat sekaligus didalamnya tujuan digunakannya rak server tersebut agar terlindunginya perangkat yang aktif selama 24 jam seperti mikrotik, switch dan server data.

\section{B. Instaksi Lantai 1}

Adapun ditahapan ini dapat dilihat pemasangan perangkat pada lantai satu yang ada diInspektorat dibawah ini : 


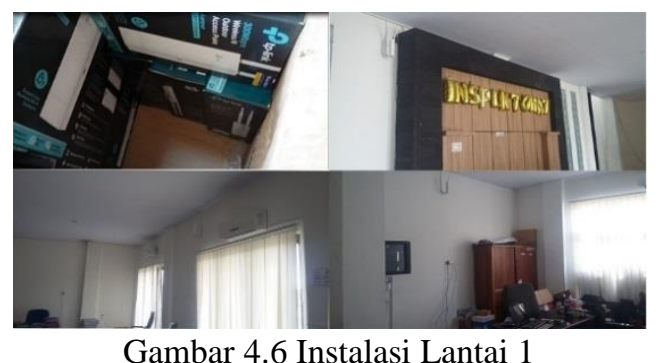

Hasil gambar diatas dapat dilihat pada point pertama menentukan perangkat yang akan di pasang pada masing-masing ruangan yaitu perangkat access point eap 110 outdoor dan perangkat ini mampu dengan jarak $3 \mathrm{Dbm}$ sehingga perangkat yang digunakan pada lantai 1 sebanyak 5 perangkat dan alasan menggunakan 5 perangkat ini karena melihat kondisi ruangan masing-masing berbeda sehingga dibutuhkan 5 perangkat agar dapat tercover kesemua ruangan yang ada pada lantai 1 tersebut hal ini telah dibuktikan apabila menggunakan kurang dari 5 perangkat, sinyal yang akan diterima sangat kurang stabil.

\section{Instalasi Lantai 2}

Adapun ditahapan implementasi ini pada instalasi jaringan dilantai dua dapat dilihat pada gambar dibawah ini :

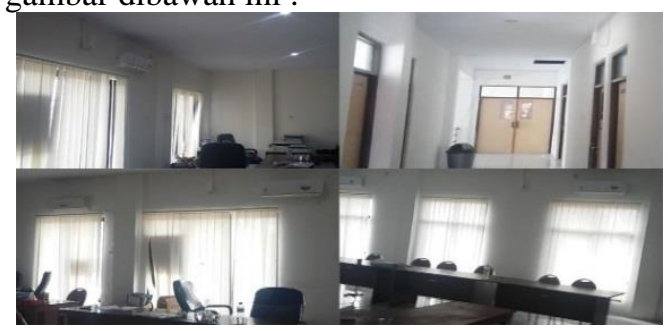

Gambar 4.7 Instalasi Lantai 2

Pada gambar diatas dapat dijelaskan bahwa instalasi jaringan pada lantai dua terdapat 8 ruangan dan masing-masing ruangan berbeda tugasnnya yaitu Ruangan Aula, Ruangan P2UPD, Ruangan Pembantu 1,2,3,4, Ruangan Auditor P2UPD dan Ruangan Pepusi yang pertama pada gambar diatas proses dari menentukan jalur kabel yang nantinya akan disatukan dalam satu jalur untuk menghubungkan perangkat access point omada selanjutnya penentuan titik tempat perangkat tersebut terpasang, dan pemasangan tiang kecil yang nantinya berfungsi sebagai tempat menempelnya perangkat, dan selanjutnya pemasangan perangkat access point omada setelah itu baru akan dihubungkan antara kabel dan perangkat tersebut dan selesainya pemasangan perangkat tesebut dapat dilihat gambar terakhir diatas.

\section{Instalasi Perangkat Access Point}

Pada tahap implementasi perangkat omada ini dapat dilihat melalui gambar dibawah ini :

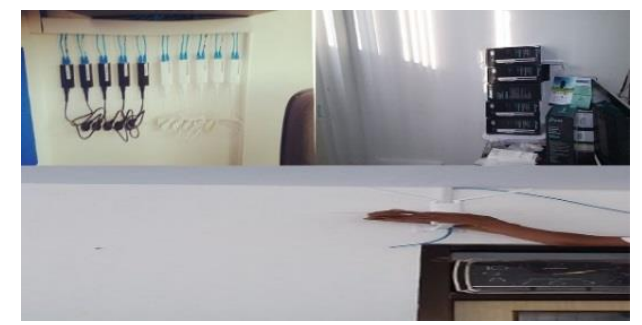

Gambar 4.8 Instalasi Perangkat Access Point

Gambar diatas menunjukan bahwa proses dari persiapan dalam pemasangan perangkat sebelum melakukan pemasangan pada titik yang telah ditentukan, kemudian pada gambar selanjutnya bahwa menentukan kabel yang akan digunakan dengan jarak posisi perangkat yang akan di pasang selanjutnya pada gambar berikut melakukan pemasangan perangkat sekaligus kabel yang nantinya akan di pasang pada perangkat itu, guna untuk menghubungkan perangkat dengan swich agar dapat berbagi data antar perangkat yang terhubung dan pada gambar selanjutnya proses pemasangan perangkat telah selesai dan terpasang dengan baik.

\subsubsection{Implementasi Konfigurasi}

Tahapan implementasi konfigurasi ini ada terdapat 3 tahap yang akan diuraikan dibawah ini seperti konfigurasi mikrotik, konfigurasi omada controller dan hasil dari kedua konfigurasi tersebut. Berikut dapat dilihat dibawah ini :

\section{A. Konfigurasi Mikrotik}

Konfigurasi mikrotik terdiri dari beberapa bagian dimulai dari login hingga konfigurasi selsai seperti dijelaskan pada masing-masing poin berikut:

1. Konfigurasi Interface ether 1

Proses selanjutnya membuat IP Address jaringan lokal etherl yang dimana IP-nya sama dengan IP Internet dapat dilihat gambar dibawah ini

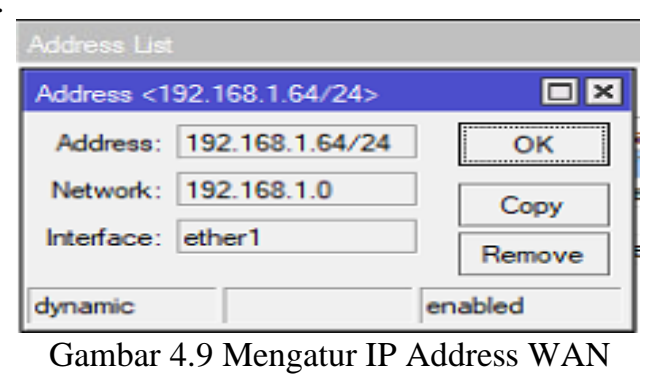

Gambar diatas dapat dilihat bahwa proses untuk memberikan alamat kepada port satu atau dapat disebut ether 1, dimana port satu ini akan difungsikan sebagai tempat jalur internet karena menyesuaikan dengan IP yang ada pada modem agar port lain dapat terhubung dengan internet walaupun berbeda alamat nantinya pada proses inilah yang dinamakan sebagai pemberian alamat IP agar mudah dikenali oleh modem. 
2. Konfgurasi Interface ether 2

Tahapan ini sama dengan tahapan sebelumnya hanya saja yang berbeda pada settingan IP dan interface-nya berikut dapat dilihat gambar dibawah ini :

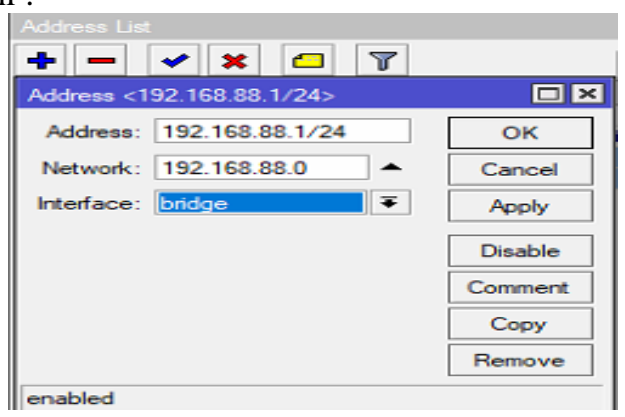

Gambar 4.10 Mengatur IP Address LAN

Pada gambar diatas dapat dijelaskan bagian dari tampilan konfigurasi pada port 2 karena penulis menggunakan port 2 sebagai jalur untuk jaringan lokal oleh sebab itulah proses ini dilakukan karena sesungguhnya perangkat yang akan menggunakan jaringan lokal ini yaitu perangkat access point omada controller dan pada gambar diatas tersebut mengapa diberi nama bridge karena ini penanda untuk menyamai port-port yang akan satu arus dengan port 2 ini, sehingga untuk pengaturan port selanjutnya tidak perlu di setting kembali karena sudah menyesuaikan dengan port 2 .

\section{Konfigurasi Gateway}

Pada tahapan selanjutnya ini merupakan bagian dari konfigurasi dapat dilihat pada gambar dibawah ini :

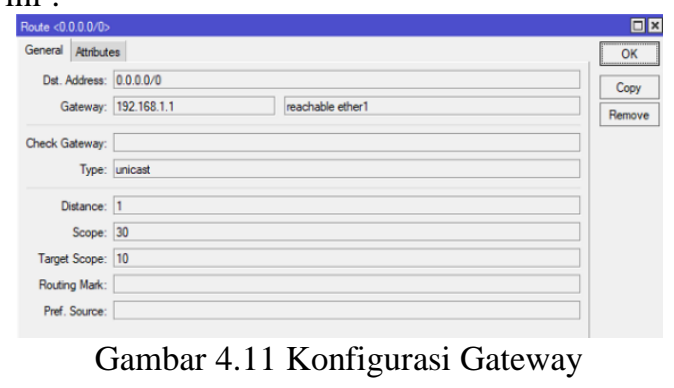

Pada gambar diatas dapat dijelaskan bahwa setelah mengkonfigurasi IP Address pada masingmasing port atau interface maka selanjutnya adalah mengkonfigurasi default gateway pada proses ini, router ISP memiliki IP address 192.168.1.1 dan internet akan diwakili oleh IP Address 0.0.0.0/0.

\section{Konfigurasi DNS Server}

Proses konfigurasi DNS Server dapat dilihat pada gambar dibawah ini :

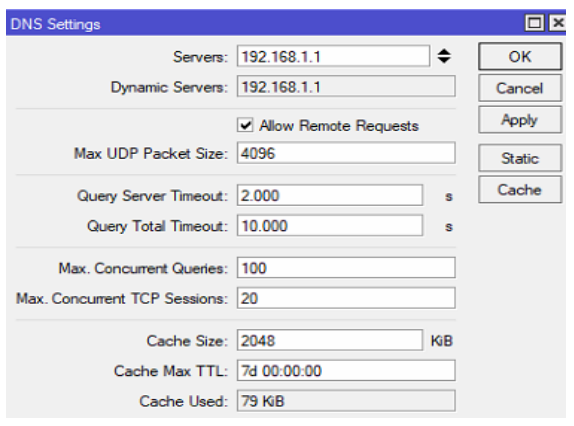

Gambar 4.12 Konfigurasi DNS Server

DNS Server yang digunakan adalah DNS Server ISP dengan IP address 192.168.1.1 perintahnya sebagai berikut : IP dns set server =192.168.1.1 allow-remote-requests=yes Opsi allow-remote-request-yes, akan menjadikan Router Mikrotik sebagai DNS Server juga. Sehingga nantinya konfigurasi DNS pada perangkat user cukup diarahkan ke Router Mikrotik, dan tidak lagi diarahkan ke DNS Server milik ISP. Teknik ini dapat menghemat bandwidth karena pertanyaanpertanyaan DNS hanya akan diberikan ke Router Mikrotik.

\section{Konfigurasi Masqurade}

Pada tahapan konfigurasi masquerade dapat dilihat pada gambar dibawah ini :

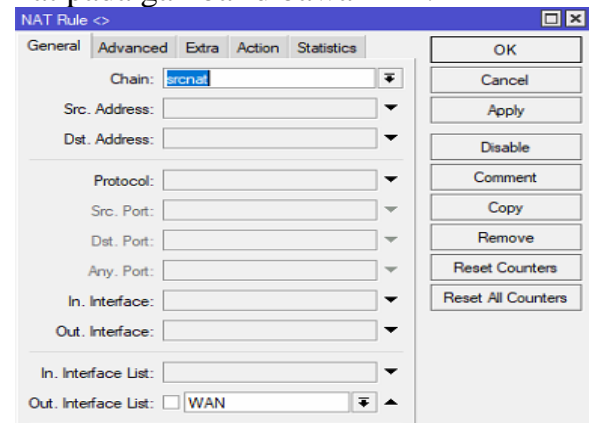

Gambar 4.13 Konfigurasi Masqurade

Pada gambar diatas dapat dijelaskan bahwa Router Mikrotik pada sekenario ini merupakan router yang berada diantara jaringan publik (internet) dan jaringan Lokal LAN. Router berada pada posisi tersebut harus menjalankan Network Address Translation (NAT) yang berfungsi mengganti IP address pada setiap paket data yang keluar dari perangkat user ( IP Address Private) menjadi IP Address publik yang ada di ether1.

\section{Konfigurasi DHCP Server}

Pada tahapan konfigurasi DHCP Server ini dapat dilihat pada gambar dibawah ini : 


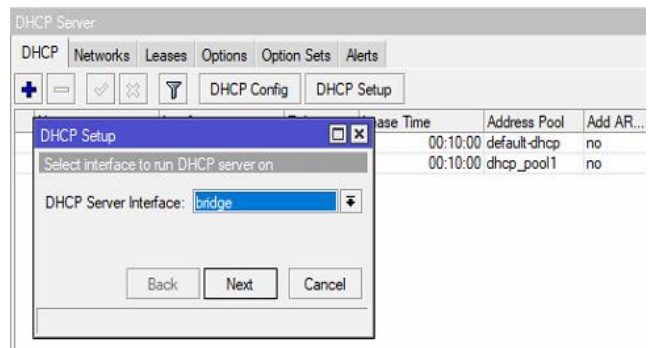

Gambar 4.14 Konfigurasi DHCP Server

Pada gambar diatas dapat dijelaskan bahwa tahapan ini konfigurasi DHCP agar tidak perlu lagi mengkonfigurasi IP address pada masing-masing perangkat user.

\section{Konfigurasi Hotspot}

Berikut ini merupakan konfigurasi Hotspot pada mikrotik dapat dilihat pada gambar dibawah ini :

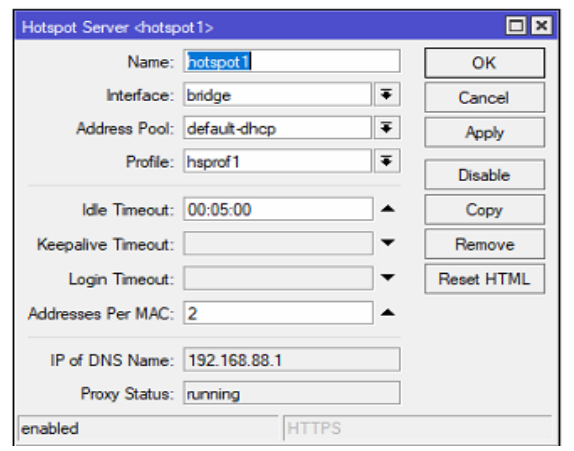

Gambar 4.15 Konfigurasi Hotspot

Gambar diatas dapat dijelaskan bahwa hasil dari settingan hostpot yang akan digunakan pada ether2 yaitu bridge dapat dilihat bahwa yang akan disetting berdasarkan nama, interface, address pool, profile dan id timeout dan ketika semua telah tersetting maka settingan selesai.

\section{B. Konfigurasi Omada Controller}

Sebagimana fungsi yang dimiliki oleh perangkat omada kontroller yaitu sebagai pengatur jaringan yang menggunakan perangkat omada maka berikut konfigurasi yang dilakukan.

\section{Omada Controller}

Pada tahap ini sebelum melakukan konfigurasi perangkat omada controller maka diperlukan aplikasi Omada controller v3.0.5 yang berfungsi untuk mengkoneksikan perangkat-perangkat access point omada controller yang telah di pasang agar mudah dalam memonitoring perangkat serta melihat proses berjalannya jaringan dan dapat dilihat pada gambar dibawah ini :

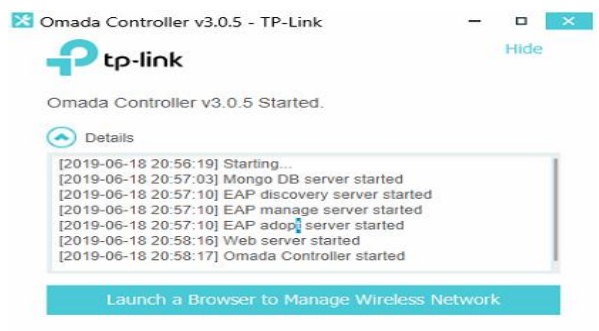

Gambar 4.16 Omada Controller

Dari gambar diatas dijelaskan bahwa ini merupakan gambaran dari menu utama aplikasi yang akan digunakan sebagai aplikasi pendukung perangkat access point eap milik tp-link omada controller dan pada aplikasi inilah yang nantinya akan memudahkan operator dari Inspektorat Kabupaten Sumbawa dalam mengelola maupun memonitoring perangkat jaringan.

\section{Halaman Login Omada Controller}

Pada tahapan ini akan dijelaskan dari tampilan halaman login yang nantinya akan digunakan untuk masuk dalam halaman aplikasi dan dapat dilihat pada gambar dibawah ini :

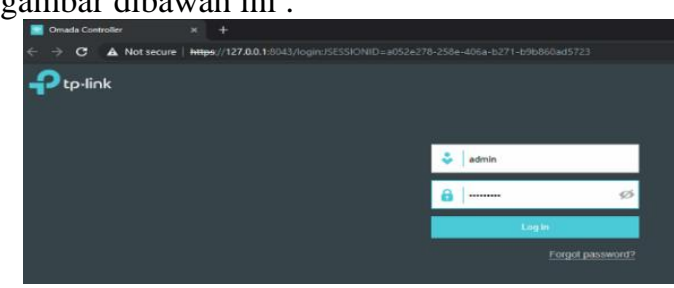

Gambar 4.17 Halaman Login Omada Controller

Dari hasil gambar diatas dapat dijelaskan bahwa ini merupakan bagian dari halaman untuk mengakses ke dalam aplikasi pada gambar diatas bahwa sudah ada tertulis username dan password karena sebelum bisa masuk ke halaman ini penulis diarahkan untuk mendaftar sebagai akun, agar dapat masuk pada halaman login sementara melihat hal ini merupakan bagian dari keamanan yang cocok untuk Di pergunakan karena tidak sembarang yang dapat masuk pada aplikasi ini kecuali sudah mengetahui username dan password.

3. Tampilan Tambah Perangkat Access Point Adapun ditahapan ini akan dijelaskan dari tampilan tambah perangkat access point dari aplikasi omada controller berikut gambar dapat dilihat dibawah ini :

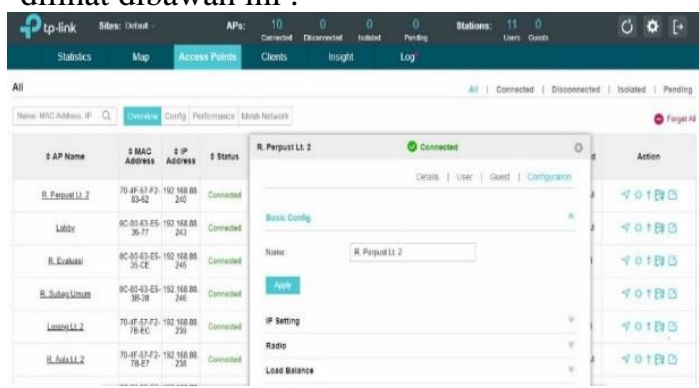

Gambar 4.18 Tambah Perangkat Access Point 
Pada gambar 4.26 diatas dapat dijelaskan bahwa tampilan dari aplikasi omada controller, kemudian pada tampilan tersebut dapat dilihat bahwa beberapa perangkat yang telah ditambahkan didalam aplikasi, yang ada pada lantai 1 dan lantai 2 sudah terbaca atau dikenali oleh aplikasi omada controller karena jumlah perangkat yang terpasang ada 10 perangkat dengan masing-masing nama yang telah diberikan dan jika masing-masing perangkat telah diberi nama maka selanjutnya memilih untuk diterapkan sehingga hasilnya akan berubah berdasarkan nama yang diberikan.

\subsection{Monitoring}

Dalam tahapan monitoring akan dijelaskan berberapa proses yang akan dilakukan untuk monitoring jaringan yang dibangun dan monitoring inilah akan terlihat keberhasilan dari tahapan sebelumnya, karena pada monitoring ini penulis maupun admin nantinya akan dapat mengetahui kesalahan atau keberhasil dari jaringan yang telah dibangun pada tahapan hasil monitoring ini akan diuraikan dalam 2 proses yaitu monitoring koneksi, dan monitoring Trafik berikut dapat dilihat uraian dibawah ini :

\subsubsection{Monitoring Koneksi}

Pada monitoring koneksi ini ada beberpa tahapan yang akan dijelaskan untuk memenuhi dari pemantauan jaringan yang telah terpasang sehingga terdapat empat sub diantaranya monitoring koneksi Client, monitoring koneksi mikrotik, monitoring dan access point, berikut dapat dilihat dibawah ini :

\section{A. Monitoring Koneksi}

Pada monitoring koneksi ini ada beberpa tahapan yang akan dijelaskan untuk memenuhi dari pemantauan jaringan yang telah terpasang sehingga terdapat empat sub diantaranya monitoring koneksi Client, monitoring koneksi mikrotik, monitoring access point, dan monitoring server data berikut dapat dilihat dibawah ini :

1. Monitoring Koneksi Client

Pada monitoring koneksi Client dijelaskan proses koneksi antara komputer admin dengan Client pada satu jaringan yang telah dirancang dan dibangun sebelumnya, karena ditahapan ini pengujian antara koneksi admin dengan Client. Berikut dapat dilihat dibawah ini :

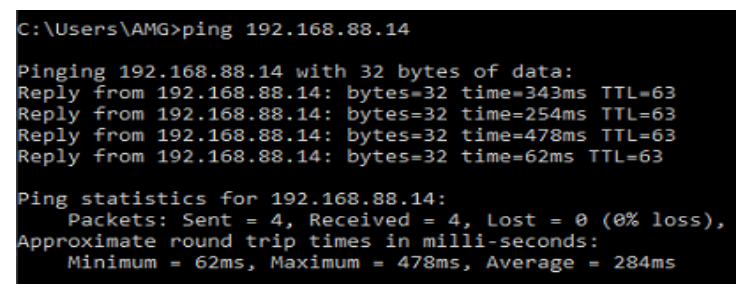

Gambar 4.19 Hasil Koneksi Admin ke Client

Hasil dari gambar diatas merupakan telah berhasilnya koneksi antara komputer admin dengan komputer Client melalui satu jaringan dengan diberikan output Reply from 192.168.88.14: bytes $=32$ time $=343 \mathrm{~ms}$ TTL $=63$ pada command prompt dan ini menandakan bahwa sudah terhubung dengan komputer Client.

\section{Monitoring Koneksi Mikrotik}

Ditahap monitoring mikrotik ini penulis akan jelaskan hasil proses yang terjadi pada mikrotik sehingga proses monitoring yang akan dilakukan Ping client yang terkoneksi berikut ini dapat dilihat gambar dibawah ini yang menunjukan antara konek yang terjadi pada mikrotik :

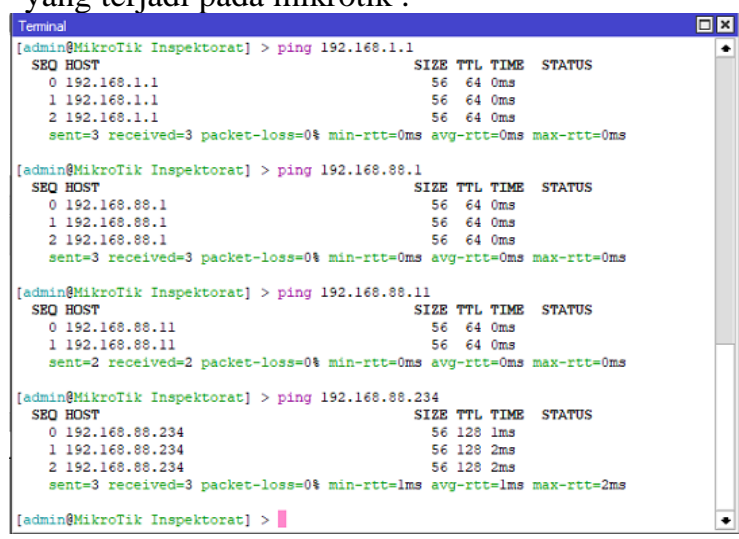

Gambar 4.20 Hasil Koneksi pada Mikrotik

Hasil pada gambar diatas tersebut bahwa telah terkoneksinya antara setiap host dari modem, mikrotik, server data dan Client yang dilakukan ping pada masing-masing ip address yang di dapat sehingga dapat dilihat pada hasil berhasilnya konektfitas diatas.

\section{Monitoring Access Point}

Pada tahap ini akan dijelaskan hasil dari proses monitoring yang dilakukan terhadap access point dan dapat dilihat pada gambar dibawah ini sebagai berikut :

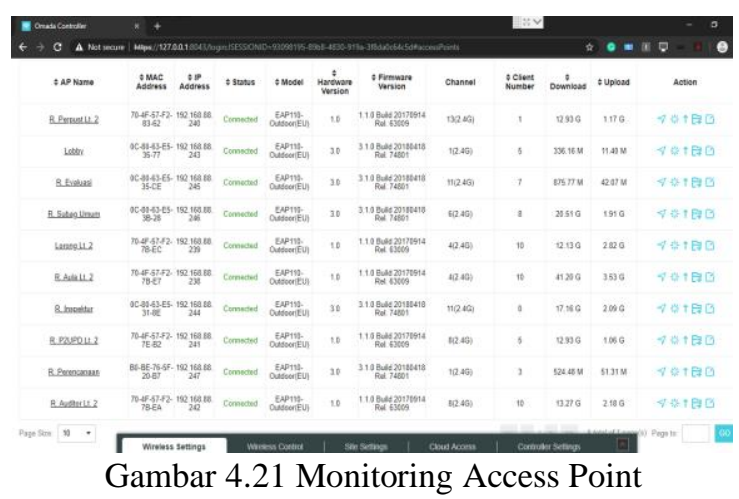

Hasil gambar diatas menunjukan bahwa telah terhubung semua access point yang sudah dipasang dengan diberikan status connected pada masingmasing access point dengan jumlah 10 access point hal ini dibuktikan pada gambar diatas yang merupakan tanda berwarna hijau dari terkoneksinya 
access point dengan prangkat switch dan router namun apabila tidak terkoneksi maka hasilnya akan terbaca disconnected dengan tanda warna merah.

\subsubsection{Monitoring Traffic}

Pada tahap ini akan dilakukan monitoring hasil traffic pada aplikasi omada controller yang telah berjalan selama user tehubung dijaringan dan dapat dilihat pada gambar dibawa ini :

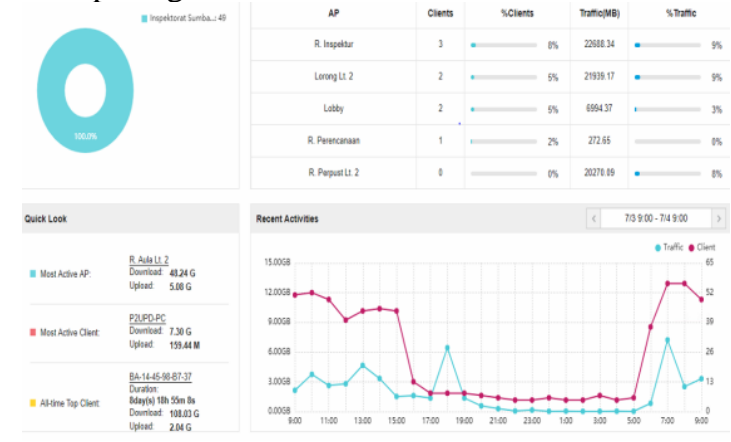

Gambar 4.22 Hasil Traffic pada Omada Controller

Dari hasil diatas merupakan bentuk dari grafik sebuah aktifitas dalam jaringan dan ini menggunakan perangkat omada controller dalam memantau traffic atau Client yang aktif dan dapat dilihat waktu penggunaan dari jam 17.00 hingga 05.00 bahwa tidak banyak Client yang aktif begitu juga dengan traffic-nya kemudian untuk yang banyak penggunaannya yaitu pada jam kerja dari jam 07.00 hingga 15.00 dapat sangat meningkat hingga mampu $12 \mathrm{~Gb}$ dalam penggunaan sehari dan ini merupakan bentuk hasilnya traffic sesuai dengan user yang aktif .

\section{KESIMPULAN DAN SARAN}

\subsection{Kesimpulan}

Berdasarkan proses perencanaan dan implementasi perancangan jaringan komputer menggunakan sistem menejemen jaringan Omada Controller pada inspektorat kabupaten sumbawa dengan metode Network Development Life Cycle maka dapat diambil kesimpulan sebagai berikut:

1. Telah selesai dirancang dan dibangun Jaringan menggunakan Sistem Manajemen Jaringan Omada Controller pada Inspektorat Kabupaten Sumbawa.

2. Akses jaringan di inspektorat saat ini telah merata disetiap ruangan karena telah dipasang access point pada lantai 1 dan lantai 2 sebanyak 10 unit dengan perangkat pendukung jaringan selain dari modem wireless seperti router, server, dan switch yang berfungsi untuk memaksimalkan layanan.

3. Telah tersedia perangkat omada controller yang berfungsi untuk memonitoring perangkat keras jaringan dan mengatur lalu lintas serta akses data pada jaringan tersebut
Dengan demikian penelitian ini dapat memberikan konstribusi untuk membantu aktifitas dan kegiatan yang dilaksanakan oleh karyawan Inspektorat.

\subsection{Saran}

Saran ini sebagai acuan terdahap penliti dan pengembangan selanjutnya guna membantu inspektorat dalam menyelsaikan masalah masalah yagn terkati dengan jaringan komputer. Adapun saran untuk kedepannya dalam penelitian ini adalah :

1. Diperlukan pembagian jaringan untuk membedakan jaringan untuk umum dan jaringan untuk karyawan agar tidak terjadi serangan yang dilakukan melalui jaringan wifi umum oleh pihak tidak bertanggung jawab untuk mendapatkan informasi penting yang berlalu lintas dalam jaringan komputer karyawan.

2. Sebaiknya dilakukan penggantian password secara berkala untuk login system, untuk menghindari terjadinya penyusupan oleh pihak - pihak yang tidak bertanggung jawab.

3. Pengecekan jaringan secara berkala diperlukan untuk menghindari terjadinya permasalahan/error pada jaringan yang dapat menyebabkan kinerja jaringan menjadi lambat.

\section{DAFTAR PUSTAKA}

[1] Arikanto, S. 2013. Procedur Penelitian: Suatu Pendekatan Praktik. Jakarta: Rineka Cipta.Jogiyanto HM. (2005). Analisis dan Desain Sistem Informasi. Yogyakarta: Andi.

[2] Endang Lestariningsih, Eka Ardhianto, W.T Handoko. 2015 Rancang Bangun Administrasi Surat Dibagian Humas Universitas STIKUBANK. Semarang: Universitas STIKUBANK.

[3] Eka Ardhianto. 2015. Rancang Bangun E-Office Administrator Agenda Kegiatan Promosi Unis Semarang. Semarang: Universitas Stikubank Semarang.

[4] Hasibuan. 2006. Manajemen Sumber Daya Manusia. Jakarta: PT. Bumi Aksara.

[5] James E. Goldman, Philips T. Rawles, Third Edition. 2001. Applied Data Communications. A business-Oriented Approach: John Wiley \& Sons.

[6] Nur Mardhiyah. 2011. Membangun Jaringan Wireless Lan Pada Kantor Kelurahan Bintaro. Jakarta: Universitas Islam Negeri Syarif Hidayatullah. 
[7] Omada Controller, (2018), Omada Pengendali Software, Dikutip dari https://www.tplink.com/us/support/download/eap-

controller/\#Related-Documents, diakses pada 05 juni 2019.

[8] Rita Setyaningrum.2018. Pengembangan Sistem Informasi Perpustakaan Pada Universitas Teknologi Sumbawa Berbasis Android. Sumbawa: Universitas Teknologi Sumbawa.

[9] Riska, Prama Wira Ginta, Patrick. 2017. Analisa dan Implementasi Wireless Extension Point dengan SSID (Service Set Identifier). Bengkulu: Universitas Dehasen Bengkulu.

[10] Yudianto, M. 2007. Jaringan Komputer dan pengertianny. Jakarta: Graha Ilmu. 